\title{
The Fruition of Decades of Good Work: An Enjoyment of Social and Physical Inclusion by Deaf Children in Upper Primary, Secondary and Preparatory Schools in Gondar City Administration, Ethiopia
}

\author{
Tadesse Abera $^{1 *} \quad$ Dait Negassa $^{2}$ \\ 1.Department of Special Needs and Inclusive Education, University of Gondar, PO box 196, Hamaya, Ethiopia \\ 2. Department of Special Needs and Inclusive Education, -Haramaya University, PO box 138,Haramaya, \\ Ethiopia
}

\begin{abstract}
The purpose of this study was to investigate the lived experiences of deaf children in upper primary, secondary and preparatory schools in Gondar City Administration. A phenomenological study design with qualitative inquiry approach was used. Semi-structured interview guide which was developed out of comprehensive review of literature was used as data gathering instrument. From thirty deaf children ( 26 children from grade 5 to 8 and 4 children from 9 to 12 grades), nine were selected through purposive and available sampling technique from upper primary, secondary and preparatory schools respectively. The data collected through semi-structured interview guide was analyzed thematically in to social and physical inclusions. Results indicated that the deaf children were found enjoying positive interaction with teachers, peers and school communities though there was communication barrier. Recommendations such as sign language training for teachers, peers and school communities and recruitment of interpreters have been forwarded.
\end{abstract}

Keywords: Deaf children, Ethiopia, physical inclusion, social inclusion and upper primary, secondary and preparatory schools

DOI: $10.7176 / \mathrm{JEP} / 10-10-02$

Publication date: April $30^{\text {th }} 2019$

\section{INTRODUCTION}

1.1. Background of the Study

The currently favored system for SWDs in Ethiopia is attendance of a unit school from grades one to four where specialist skills including sign language, braille and mobility are taught. After this point the student should be transferred into mainstream/integrated classes. Despite this system of partial inclusion being introduced in 2006 the resources, assistance and accessibility required are still primarily in urban areas and as such SWDs often travel to these areas to gain an education (UNESCO, 2015; Wilson, 2000 as cited in Anonymous, 2016).

Though encouraging track records on the education of deaf children in the country have been documented, studies are still revealing that the children are facing a number of challenges at upper primary, secondary and preparatory schools. For example (Alemayehu, 2000; Tadesse and Lynne, 2015, Aynie, 2016; Alemayehu, 2016) in their studies indicated that the status of sign language in Ethiopia is very low, though teachers were caring and accepting. The studies particularly revealed that teachers were professionally unprepared/incompetent, lack sign language competence and sign language interpreters do not have subject matter knowledge and the children face a lot of challenges ranging from social to academics. The worst is, as a result of the interconnected challenges mentioned in the preceding, the number of deaf children is declining significantly/dramatically when looked from $\mathrm{KG}$ to higher education institutions (Alemayehu, 2016). Equally worrisome fact is, there are no sign language interpreters in the country except in the capital city, Addis Ababa (Mulat, Savolaine, Lehtomaki and Kuorelahti, 2015).

Hence, studies such as the present one need to be undertaken in investigating the deaf children's lived experiences of social and physical inclusions in upper primary, secondary and preparatory schools aiming to come out with findings that help government, parents, educators, professionals and significant others as stake holders in the area to help their effort of realizing the inclusion of deaf children in the schools.

\subsection{Statement of the Problem}

Abebe (2000) in Addis Ababa and Adama in his study to see the attitude of teachers and students without disabilities towards the integration of students with hearing impairments in upper primary schools (grades 5 to 8). He found that students without disabilities had a positive attitude towards deaf children where as the teachers' were negative. The disfavors of the teachers were attributed due to their communication and competence problems to meet the educational needs of the deaf children. However Asrat (2013) in Bahir Dar City Administration primary schools and Tadesse and Lynne (2015) in North Gondar came up with findings indicating contrary point to Abebe's (2000) finding. They found that teachers had a positive attitude toward the 
integration of deaf students. But, they depicted the classroom environment and the teaching methodologies used were not helping the academic and physical inclusion of the deaf children. Lately, a study by Berhanie (2017) in Bahir Dar City Administration revealed that deaf students were not included in physical education. In other words, they were excluded from social, academic and physical inclusion.

In the country many studies, for example (Deginesh and Asrat, 2016; Mulat, et.al.2016; Mekonnen, Elina and Hannu, 2018; Belay, Fantahun, and Missaye, 2015; and Nitsuh, 2008) reveal that deaf children's education in the country is of mixed nature having both challenges and opportunities. However, the studies agree that the inclusion of the children is less likely to happen in the near future and they recommend bottom up initiative, culturally sensitive, cost effective and community resource based approaches.

Specifically in Gondar City Administration studies conducted in the area are limited and were only focused in primary schools. For example, (Tadesse and Lynne, 2015) found that in Ethiopia while the expected age for completing grade 8 is 14 years; the researchers found that almost all of the deaf students participating in the study were older than 15 years and the majority were still in grade 7 .

The pressing problem that initiated the present study is the existing scenario that the number of deaf children perusing their secondary and preparatory education is quite low as revealed from communication made with schools in the study area in particular. And, those studies conducted on deaf education in the country for example Abebe (2000), Alemayehu (2000), Tadesse and Lynne (2015), Nitsuh, (2008), Aynie, (2016), Belay, Fantahun, and Missaye, (2015), Alemayehu, (2016), Berhanie, (2017), Deginesh and Asrat (2016), Mulat, et.al. (2016) and Mekonnen, Elina and Hannu, (2018) their studies did not focus on social and physical inclusion of the deaf children in depth, the researchers rather tended to study single aspects of inclusion of the deaf children either classroom environment, teachers' attitude, peers' attitude, participation in physical education, communication and or factors affecting the education of the deaf children in general. Hence, the current study is believed to bridge the existing research gap in the country. Also, understanding the deaf children's existing inclusion opportunities and challenges will serve as an input for future facilitation of concerned ones in realizing the full inclusion of deaf children in the country.

\subsection{Research Questions}

To meet the purpose of the study the following research questions were raised:

1. How do deaf children express their lived experiences on social inclusion?

3 How do deaf children express their lived experiences on physical inclusion?

\section{Review of Related Literature}

\subsection{Opportunities and Challenges for Deaf Education in Ethiopia}

The first schools for the deaf in Ethiopia were established in the 1960s. The children were taught either in sign language or spoken language. However, these schools were not established with the idea of making DHH students literate citizens who could become full participants in society; rather, the aim was to teach them the Bible (Tibebu, 1995). According to Abeba (1996, cited in Tilahun, 2009), the first method of communication for the deaf in Ethiopia was American Sign Language (ASL), which used for 10 years from 1975 to 1986 , combined with Amharic signs and speech. From 1986 to 1989 deaf education was characterized by oral methods brought to Ethiopia by a British missionary emphasizing the philosophy that deaf children can talk (Tilahun, 2009).

\subsubsection{Laws and Proclamations}

The government of Ethiopia has almost always supported the United Nations conventions on human rights in general and the rights of persons with disabilities in particular. This trend dates back to the time of the monarchy when the Imperial regime ordered (order No 70/1971) that the definition of disability should match the international standard and set up an administrative body for disabled people. However, most of the laws and policy actions in relation to persons with disability that exist today were enacted following the arrival of the current regime (Ministry of Labor and Social Affiars, 2010).

The Ethiopian constitution established universal right to education for all groups in society. Articles 41 and 91 of the constitution emphasize the need to allocate resources for assisting people with special needs (Ministry of Labor and Social Affiars, 2010). The Ethiopian civil code provides several articles (Article 340, 1728, 48-49, 162) relating to criminal and civil legal cases that involve persons with disabilities. The articles provide various protections for persons with disabilities so that they are not disadvantaged in court. In general, all the provisions are focused toward giving aid to the person with disability (Ministry of Labor and Social Affiars, 2010). The provisions imply that people with disability lack full control of their actions and hence cannot control their own affairs. While this could be true in many situations, it is a gross characterization that may not necessarily hold true in individual cases.

Ethiopia signed the United Nations Convention on the Rights of Persons with Disabilities in March 2007 (Getachew, 2011) and ratified it in July 2010 (UN, 2012, cited in Sunayna, Jihan \& Joane, 2013). In addition, 
Ethiopia has ratified the convention on All Forms of Discrimination against Women, the Conventionon Civil and Political Rights the Convention on Economic and Social and Cultural Rights (Sunayna, Jihan \& Joane, 2013), and the Convention on the Rights of the Child. The Convention on the Rights of the Child states that all state parties have respect and ensure the rights of each child, without discrimination of any kind, irrespective of the child's or parent's disability (Article 2). Besides that, the Convention focuses on disability in article 23, mentioning the rights of disabled children to a full and decent life, special care, assistance and access to health care services, education, training, rehabilitation, and preventive information.

The Transitional Government of Ethiopia adopted the United Nations Convention on the Rights of the Child on December, 1991. The Constitution of the Federal Democratic of Ethiopia Article 9 (4) states that all international agreements ratified by Ethiopia are an integral part of the law of the land. Article 13 elaborates that all legislative, executive and judicial organs have the responsibility to respect and enforce what is embodied under that section, which should be done in conformity with human rights considerations. Furthermore, policy documents on health, education and social welfare articulate statements that uphold the protection, care, health and optimal development of children within their sphere of influence (Tirussew, 2005).

The Education and Training Policy, by confirming the importance of early childhood education, proclaims that "Kindergarten will focus on all-round development of the child in preparation for formal schooling" (Education Structure No. 3.2.1). While this provision is meant to address the needs of all children, the policy recognizes the needs of students with disabilities: "Special educational and training will be provided for people with special needs" (Education Structure No. 3.2.9). The document further confirms that efforts will be made "to enable both the handicapped and the gifted to learn in accordance with their potential and need (Education Structure No. 2.2.3) (Tirussew, 2005).

The Developmental Social Welfare Policy (1996) affirms that all efforts shall be made to implement all international and regional conventions and legal instruments concerning the rights of children Ethiopia has already accepted that protecting and ensuring the healthy development of children deserves special attention. It elaborates that "appropriate and comprehensive care and services shall be extended to children so as to ensure their all-rounded and harmonious development" (Article 5.1.1). Similarly, with regards to the needs of orphan children, the policy clearly aims to facilitate conditions that will "enable orphan and abandoned children to get the assistance they need and to eventually be self-sufficient (Article 5. 1. 7). Finally, the policy declares that all efforts shall be made to protect against children from abuse and neglect (Article 5.1.10) (Tirussew, 2005).

Ethiopia's, inclusive education strategy (Ministry of Education, 2012, p. 12) has as an objective, "Build an inclusive education system which will provide quality, relevant and equitable education and training to all children, youth and adults with special needs education and ultimately enable them to fully participate in the socio-economic development of the country"

\subsubsection{Emergence of Special Needs and Inclusive Education Offering Higher Education Institutions}

Beyond the legal frameworks, teacher education colleges in Ethiopia offer an 'Introduction to Special Needs Education' course to all future teachers, giving them the opportunity to obtain knowledge and skills on how to work with deaf students. This introductory course includes topics such as visual impairments, hearing impairments, mental retardation, language and communication disorders, physical disabilities and health-related disorders, emotional and behavioral disorders, learning disabilities, and gifted and talented students. These topics are treated independently and are sequenced in the following manner definition, type, character, cause, identification and assessment, and educational and psycho-social interventions. This introductory class, however, does not provide, the trainee teachers with deep knowledge and skills in all disabilities_ in terms of providing appropriate services to these children.

A few teacher education colleges offer diploma training in special needs education. The graduates are assigned as teachers in primary schools for children with various disabilities. Mainly they are assigned to regular primary schools that have separate classes for students with visual and hearing impairments and intellectual limitations. There are five universities that offer B.A, M.A, and Ph.D degrees in special needs and inclusive education (Addis Ababa University and Haramaya University are the only ones that offer doctoral degrees in special needs education and inclusive education, whereas Bahir Dar, Gondar, and Dilla offer up to master's level). Graduates of these colleges and universities are playing pivotal roles in improving the education and quality of life of deaf children, youths, and adults in the country. Apart from teacher training colleges, the colleges that offer certificates in special needs education and the universities mentioned above give comprehensive courses in special needs education for different types of special needs students.

There is no specialization in deaf education at the certificate, bachelor, master's, or doctoral levels. The contents of the bachelor's and master's programs are disability specific (e.g. hearing, visual, behavioral, speech, intellectual, learning, health and motor-related, and gifted and talented). There is also practicum in special needs education courses, research courses, and common courses such as Information and Communication and Technology, English writing skills, and the like. Bachelor's prepared teachers mostly work in primary schools, high schools, and education offices and in nongovernmental organizations that offer services to special needs 
children. Master's and doctoral-level graduates work in teacher education colleges, universities, and public offices and in nongovernmental organizations.

\subsection{Inclusion of Deaf Children}

\subsubsection{Social Inclusion of Deaf Children}

Social inclusion of deaf children in this study consists of favorable teachers' attitude, interaction of deaf children with their peers, teachers and the school communities.

\subsubsection{Teachers' Attitudes}

Recently, studies came up with findings that indicated the attitude of regular teachers have turned out from what has been negative to positive (for example, Prakash, 2012; Eriks-Brophy and Whittingham , 2013; Alshahrani, 2014 as cited in Aseery, 2016 and Aseery, 2016).

AlShahrani (2014) as cited in Aseery (2016) examine the attitudes of 120 Saudi educators toward the inclusion of deaf and hard-of-hearing students in regular schools in Jeddah. The results indicated that the participants held positive attitudes toward including hard of hearing students in regular schools but less favorable attitudes for including deaf students. The majority of participants considered special institutions for the deaf to be the best educational setting for these deaf students.

Eriks-Brophy and Whittingham (2013) investigated teachers' attitudes towards inclusion and their experience of teaching deaf and hard-of-hearing students in regular classrooms. The findings indicated the majority $(80 \%)$ of the teachers agreed that regular education classroom was the appropriate educational option for most deaf and hard-of-hearing students. The teachers also showed high confidence in their ability and knowledge to teach students with hearing loss and were satisfied with the support they received from the school. However, they felt the pre-teaching programs were insufficient and agreed that inclusion increased their workload and responsibilities. Prakash (2012) in india found most teachers are agreeable to the inclusion of deaf students in their classrooms.

However, studies indicate, still the teachers' attitude towards the inclusion of deaf children is under the influence of many conditions. For example, in contrast, in a case study of two deaf and hard-of-hearing students included in secondary schools in the Netherlands, Vermeulen, Denessen, and Knoors (2012) found that many classroom teachers had positive attitudes about the inclusion of students with hearing loss, especially if the students behaved well and put forth their best effort to succeed academically. This result is consistent with the common belief that behavioral problems create challenges for teachers in inclusive settings. Prakash (2012) identified variables like gender, teachers' experience, and qualification that contribute to the conflicting attitudes toward including deaf and hard-of-hearing students in regular education schools.

\subsubsection{Interaction with peers}

Interaction is the mutual understanding and attention between two or more people. Interaction is characterized by individuals providing and sharing ideas, co-operating with one another, challenging each other's conclusions, and reasoning in order to promote higher quality decisions (Mlay, 2010).

Musengi and Chireshe (2012) in rural primary schools of Zimbabwe deaf students participated in most outof-class activities with hearing peers. It was concluded that the deaf students were socially included but were academically excluded because of lack of linguistic access to the academic curriculum in the primary schools. Mlay (2010) in Tanzania found out that learners who are hard of hearing interact favorably with their hearing peers despite the verbal communication barriers that exist. For example During the Physical education lessons the hard of hearing learners join and interact with others in various games. They used to go out both hearing and hearing impairment learners. They used to play together some games such as playing with toys, soccer, running, skipping, cards, and other kinds of games at their age, although there were some games under their age (Mlay, 2010. P. 50-51).

Hung and Paul (2006) investigated the views of hearing students at an Ohio state secondary school on the inclusion of Deaf or hard-of-hearing peers in their general education classes. They found that the majority of subjects showed a positive attitude towards the inclusion of DHH peers. Alasim (2018) in his study depicted that Deaf and hard of hearing students face barriers that concern their participation and interaction in the general education classroom. The reason for it is, Spoken language difficulties for $\mathrm{d} / \mathrm{Deaf}$ and hard of hearing students are the greatest barriers that limit the participation and interaction of those students (Alasim, 2018).

In short, it seems possible to argue that except communication barriers deaf children have positive interaction with their peers (Tadesse and Lynne, 2015).

\subsubsection{Interaction with Teachers and School Communities}

Findings indicated mixed as both positive and negative interactions of deaf children with their teachers and other communities of the schools. For example, Tadesse and Lynne (2015) found that deaf children had a very positive interaction with their teachers. Their teachers were accepting, caring and supportive. Also, Asrat (2013) found positive attitude of teachers towards the integration of deaf children.

On the other hand, Abebe (2000, p.115) in his study concluded that, "the majority of hearing-impaired 
students [students with hearing impairments], regular class and special class teachers have a negative attitude towards the integration of students with hearing impairments in to regular classes. in other words, the interaction of deaf children with teachers and school communities is not good. Contrary to this Asrat (2013) found positive attitude of teachers towards the integration of deaf children.

However, findings indicated that positive interaction can prevail if necessary awareness creation and equipment with relevant knowledge and skills is made among teachers and school communities. Supporting this idea, Alasim (2018) in United States of America in his study concluded that facilitation of participation and interaction of deaf and hard-of-hearing students in the general education classroom requires the knowledge and skills of the schools' staff, including teachers and interpreters. He added, the teachers' awareness and attitudes toward deafness and inclusion are important to increase the participation and interaction of $\mathrm{d} /$ Deaf and hard of hearing students in the general education classroom. In addition to this, most obstacles that deaf and hard-ofhearing students encounter in the general education classroom can be addressed when the entire school staff works together and provides all possible support to those students (Alasim, 2018).

\subsubsection{Physical Inclusion}

Physical inclusion in this study consists of teaching and learning materials, school building and infrastructure and seating arrangements.

\subsubsection{Teaching and Learning Materials}

Support materials used by teachers during the teaching process include text and reference books, wall maps, charts and science kits. They are crucial in facilitating the effectiveness of the learning of deaf students and other disabilities (Posi, 2006). Study carried out by Mapsea (2006) showed that, in most regular schools where students with disabilities were integrated, the required materials were inadequate.

Ample studies indicated deaf children are facing a number of challenges in this regard. For example, All the deaf students had hearing aids and were mostly taught by regular class teachers in the mainstream but with constant withdrawal to the resource rooms for specialized services such as auditory training. Despite wearing hearing aids most deaf students could not hear the spoken languages used by teachers (Musengi and Chireshe, 2012).

Furthermore, Musengi and Chireshe (2012) in their study in Zimbabwe although socially benefiting, the practice was faced with many challenges. Measures such as learning some signs in a dictionary, on a chart or occasionally having a specialist 'interpreting' for the deaf learner are inadequate to include the deaf learners into the mainstream learning activities. In addition to this, the provision of hearing aids and audiometers for the children with sensory impairments is not adequate (Hayes, 2009).

In Ethiopia, there are similar findings. For example, Tadesse and Lynne (2015) in their study indicated, most (70\%) deaf children indicated there was insufficient learning materials in the school and a strong majority $(86.67 \%)$ of the deaf and hard-of-hearing children disclosed they believed they were not learning as well as their peers. As a result, most of the children $(63.33 \%)$ reported they did not feel proud of their current educational performance. Deginesh (2016) in her review of related literature confirmed that there is absence of resources centers in almost all public schools were deaf children attend their education. Moreover, (Berhanie, 2017) finding indicated that unavailability of appropriate facilities and equipments, absence of teachers' CPD training on inclusive physical education, the text / teachers guide book not modified or adapted to meet the need of special students.

\subsubsection{School Building and Infrastructure}

Ainscow, (1995) as cited in Gudyanga et.al (2014) suggested the ideal physical environment for students with hearing impairments. The classrooms should be away from noise and controlled for acoustics that affect hearing aids. There is need to add carpets, window treatments, or acoustical wall/ ceiling coverings to absorb sound and reduce noise from furniture scrapping on hard surfaces by attaching rubber shoes to the legs of students' desks and chairs. The classrooms should also be well lit to enable the hard-of hearing and deaf students to speech read and to read the signing. Besides the acoustically treated classrooms, speech rooms and auditory training centers should be available.

Contrary to the above principle, schools especially in developing countries are not able to accommodate for deaf children accessible conducive school building and infrastructure. For example, Studies conducted in Tanzania and Uganda have shown that there are not enough buildings, especially classrooms, in schools for students with disabilities, including those with hearing impairments (Mapesa, 2006). These researchers found that many of the classes in schools for SWDs were overcrowded with most of them having more than 40 students.

Furthermore, Mapolisa (2013) in Zimebabwe found out that there were very limited resources to cater for children with hearing impairments. The children lack acoustically treated rooms and hearing aids to suit their learning needs. Thus, most of the infrastructure in the regular schools did not meet the fundamental requirements of children with hearing impairments. In addition to this, Kapp (1991) as cited in Gudyanga et.al (2014) points out that secondary school buildings and classrooms, should be designed and equipped in such a way as to harmonize with the personal and didactical needs of deaf students. The existing infrastructure at regular 
secondary schools offering inclusive education needs to be adjusted to accommodate all learners' needs. In Ethiopia, Asrat (2013) depicted that in all study settings were not conducive to enhance inclusive education practice.

\subsubsection{Seating Arrangement}

The classroom for deaf students should have semi-circular seating. Sitting in semi-circle is emphasized during lessons because the hearing impaired students cannot hear what others say if the speaker is not seen. Van Uden (1977) recommended that the deaf students sit in a semi-circle during learning because all of them depend on visual rather than auditory cues.

Van Uden (1977) added that, the number of students must be smaller in the class, proposing that five partners in the class is the optimum number of effective conversation, since every time during a lesson students very often look to the left and to the right in order to catch what has been said. The teacher's seat is at the centre of the students' seats which have arranged in semi circulars shape to make it easier for teacher to monitor individual students' learning differences and also to make it easier for each student to read the teacher's lips. Or some students may require lip reading to reach a normal level of comprehension and these will need preferential seating arrangements, (Chimedza and Peterson, 2003; as cited in Gudyanga et.al, 2014).

An effective seating arrangement can enable students who are deaf and hard-of-hearing to see other students and the teacher easily, to participate in both individual work and group activities, and to follow classroom discussions easily (Trussell, 2008).

\section{Research Methodology}

\subsection{Research Design}

The research design for this study was phenomenological design, which is hermeneutical phenomenology. Hermeneutical phenomenology is the study of personal experience and requires a description or interpretation of the meanings of phenomena experienced by participants in an investigation (Creswell, 2013). According to van Manen (1990) as cited in (Allen, 2013), hermeneutic phenomenological research is a "search for the fullness of living" (p. 12). That is, the aim is to acquire a richer and deeper understanding of an everyday human experience, in our case deaf children experience of inclusion in schools (van Manen, 1990, 1984a; 1984b; 1990; as cited in Allen, 2013). (Maxwell, 2005) further added, the goal of hermeneutic phenomenological research is a form of qualitative inquiry to develop rich and deep textual descriptions of participant experiences while also allowing for an interpretive element of the data based on the researcher's theoretical and personal knowledge. So in this study the experiences of the deaf children in their social, academic and physical inclusions has been thoroughly covered and analyzed and finally evidence based interpretation, meaning and analysis were made using previous studies conducted on deaf children nationally and internationally along with its discussion of findings on their similarities and differences with previous study findings and new findings of the research were also emphasized.

\subsection{Sampling Technique}

In Gondar City Administration there are 46 primary schools, 5 secondary schools and 4 preparatory schools referred as public schools totaling 55 schools where deaf children can attend their education in the city. 1 primary school (Tsadiqu Yonannes), 1 high school (Ayer Tena) and 3 preparatory schools (Hidar 11, Debreselam and Fasiledes), totaling 5 schools were taken for this study through available sampling technique. The only justification for selecting these schools was, at the time of the current study deaf children were found only in the mentioned public schools in the city. The list of all deaf students in the city is recorded in Tasdiqu Yohannes primary school document office, and they are monthly paid. All the deaf children have been medically approved on their deafness.

In all the mentioned schools starting from grade 5 to 12 except in grade 10 there were totally 30 students who are 10 females and 20 males (in grade 5-8=26 deaf children; in grade $9=1$ deaf child; in grade $11=2$ deaf children and in garde $12=1$ deaf child). With regard to the sample from 30 deaf children only 9 children ( 7 females and 2 males) were taken based on purposive sampling and available sampling techniques. Purposive sampling technique, using perfect sign language skills as a sole criteria, was used to select 5 deaf children in upper primary schools as their number was relatively large than those in secondary and preparatory schools (26:4). Available sampling technique was used to take all the 4 deaf children in secondary and preparatory schools.

Hence, from Tsadiqu Yohannes primary school from 26 deaf children (in grade $5=5$ deaf children; in grade $6=8$ deaf children; in grade $7=7$ deaf children and in grade $8=6$ deaf children) two from grade 8 and one from each grade, totaling 5 deaf children were taken. From Ayer Tena high school (in grade nine, 1 deaf child), from Hidar 11 preparatory school (in grade eleven, 1 deaf child), from Debreselam preparatory school (in grade eleven, 1 deaf child) and from Fasiledes preparatory school (in grade twelve, 1 deaf child) totaling 4 deaf children were taken. Totaling for this study, 9 deaf children were taken. Qualitative sample sizes are usually small and purposeful (Maxwell, 2005). 
With regards to demographic characteristics of the deaf children, it was seen in terms of sex, age, on set of impairment, cause of impairment and sign language skills of parents/care givers. Cases were referred anonymously in their grade levels in the presentation of results and discussion. Thus, here, biographical presentation would follow the same mode. Hence, case 5 is female who is 17 years old. Her deafness occurred after birth due to injury of ear. Her parents do not have sign language skills. Case 6 is female who is 15 years old. Her deafness occurred after birth. Her deafness resulted in ear infection. Her parents do not have sign language skills. Case 7 is male aged 18. His deafness occurred congenitally with unknown causes. Among his family only his brother attempts signing. Case $8 \mathrm{~A}$ is female who is 17 years old. Her deafness occurred congenitally with unknown causes. Her parents do not have sign language skills. Case 8B is female aged 17. Her deafness happened congenitally. Her parents do not have sign language skills. Case 9 is female aged 19. Her deafness occurred adventitiously with unknown cause. Her mother tries sign language. Case 11A is male aged 20. His impairment occurred congenitally with unknown cause. His parents do not have sign language skills. Case 11B is female aged 18. Her impairment is congenital with unknown cause. Her parents attempt sign language skills. Case 12 is female who is 18 years old. Her impairment is congenital with unknown cause. Her parents do not have sign language skills.

\subsection{Data Collection Instrument}

The most appropriate data collection strategy for a phenomenological research is the profound interview with open or semi-structured interview questions. These two types of interviews allow the researcher to address the phenomenon profoundly, providing a space of opportunity for the informants to express their experiences in detail, approaching reality as faithfully as possible. The detailed descriptions or interpretations brought by the participant in the profound-phenomenological interview should be as representative of experienced reality as possible (Padilla-Díaz, 2015, p. 104)

Semi-structured interview guide was developed by the researchers after comprehensive review of related literature on social and physical inclusion. The developed instrument was validated by two teachers in special needs education who are working in special unit of Tsadiqu Yohannes primary school which was one sample school of this study. These two teachers were also data collectors at the same time.

\subsection{Ethical Considerations}

First of all, participants were asked their agreement to gain their informed consent. Participants were informed that their information will remain confidential and will be used for academic purposes. Sign language interpreters recruited for data collection has played the role of receiving consent agreement and ensuring confidentiality. In the end, data presentation and analysis was made based on the available data from respondents.

\subsection{Data Collection Procedures}

The following procedures were used while collecting data: letter of permission from department of Special Needs and Inclusive Education from University of Gondar was taken and was given to the schools' principals; two data collectors who were with perfect sign language skills were recruited in communication with the principal of Special Unit of Tsadiqu Yohannes primary school. In the school, special needs education professionals are available in large number than in any other in the city; as the school is the only inclusive school in the city. The two data collectors are female teachers with ample experience of working with the deaf children. Both are graduates in special needs starting from certificate from Sebeta and Debre Birhan. Currently, both are attending their masters and bachelors degree in special needs education at University of Gondar in summer program; through the help of the recruited two professional teachers the objective of the research was clarified to deaf children and respondents were selected and consent of agreement was reached; good rapport was established with willing respondents through the support of the recruited teachers; respondents were interviewed in their schools. During the interview sessions when one teacher interviews the other teacher takes mobile video records. Almost, each interview took a maximum of 40 minutes; the data collection and the translation took starting from December 11 to December 24. Then, the researcher made translations from Amharic to English language with maximum accuracy and then results and discussion was made based on the available data.

\subsection{Methods of Data Analysis}

Colazzi's (1978, p. pp.48-71) as cited in Schuemann (2014) phenomenology data analysis model highlights conceptual patterns any researcher in phenomenological research to follow in the analysis phase. Hence, this research in its analysis was guided by the guideline of Colazzi's (1978, p. pp.48-71) cited in Schuemann (2014) the following steps guided the current study's data analysis: the researcher thoroughly reads and rereads the transcribed interviews to identify with the data and to acquire a sense of each individual experiences; from the transcripts the researcher identifies significant statements which pertain directly to significant phenomena; the researcher develops interpretive meanings of each of the significant statements. The researcher rereads the 
research protocol to ensure the original description is evident in the interpretive meanings; the interpretive meanings are arranged into clusters, which allow themes to emerge. The researcher seeks validation, avoids repetitive themes, and notes any discrepancies during this process; the themes are then integrated into an exhaustive description. The researcher also refers the theme clusters back to the protocols to substantiate them; the researcher produces a concise statement of the exhaustive description and provides a fundamental statement of identification also referred to as the overall essence of the experience and The reduced statement of the exhaustive description is presented to the study's participants in order to verify the conclusions and the development of the essence statement. If discrepancies are noted, the researcher should go back through the significant statements, interpretive meanings, and themes in order to address the stated concerns.

Therefore, the analysis was made beginning from transcribing the interview data by the two data collectors from mobile recorder to written document in Amharic about each respondent deaf child across all dimensions of inclusion in academic, social and physical totaling twelve sub-components. Then translation into English language was made by the researcher; then every interview quotation was categorized based on their themes to academic, social and physical; then description and interpretation was made based on three major themes academic, social and physical inclusion of the deaf children and then meaning was made in comparison with previous research findings and meanings arising from the emerging themes. In all the process re-reading of translation of themes, selection of frequented ideas, explanations and themes; comparison, avoiding redundancies, reducing of statements and concerns of the deaf children were highly emphasized.

\section{Results and Discussion}

The results and discussions have covered in providing answers to the major three research questions raised in the beginning of the study. The first question was about the social inclusion of the deaf children (concerned about teachers' attitude and about the deaf children's interaction with peers, interaction with teachers and school communities). The second question was regarding the physical inclusion of the deaf children (concerned about the deaf children's experience on areas of teaching and learning materials, school building and infrastructure and seating arrangement.

In presenting the cases, to keep confidentiality anonymity was followed. In doing so, as there were 9 cases, case naming was given based on grade levels. Hence, here after, we will have names of case 5, case 6, case 7, case $8 \mathrm{~A}$, case $8 \mathrm{~B}$, case 9 , case $11 \mathrm{~A}$, case $11 \mathrm{~B}$ and Case 12 for respondents of deaf children from grade five, six, seven, eight, nine, eleven and twelve respectively.

\subsection{Social Inclusion}

\subsubsection{Teachers' Attitudes}

The deaf children were asked, “How do you see your teachers' attitude towards you?" The respondents replied that their teachers had positive attitude. This is a consistent finding with previous study findings for example, Prakash (2012), Eriks-Brophy and Whittingham (2013), Alshahrani (2014) as cited in Aseery (2016) and Aseery, 2016) that indicated the attitude of regular teachers have turned out from what has been negative to positive. Also, in Ethiopia studies such as Asrat (2013) and Tadesse and Lynee (2015) confirmed the same scenario.

However, as studies depicted (for e.g., Eriks-Brophy and Whittingham, 2013; Prakash 2012; Denessen, and Knoors, 2012; Kauffman and Hallahan, 2005) the attitude of teachers towards deaf children is dependent in various factors such as communication, students' effort, students behavior, qualification, experience and the like. What was discovered in this study as a true factor influencing teachers' attitude was communication (lack of sign language skills of teachers). Consistent with this finding Tadesse and Lynnee (2015) in their study confirmed that though teachers were accepting and caring, their attitude towards deaf children was highly influenced due to lack of sign language skills. Manifested in lack of belief deaf children will not perform better in their academics due to the children are taught in different language other than their language-sign language. In this regard, case 8B gave a clear picture of the scenario. She said;

Many of the times some teachers have an attitude mixed with desperation and recklessness due to the fact that they have a thought of they cannot communicate at all. As a result, they think no matter what they burden themselves in giving us support, we will never be benefited out of it.

Case 8A added there are also differences in subject teachers. She said;

Especially teachers of mathematics and English subjects due to the their desperation that they cannot communicate with us they have never seen our exercise books with focus and do not try to support us. However, other teachers for example HPE and Geography teachers try to communicate with us and when we attempt they encourage us.

Nevertheless, on average, though there is communication barrier the teachers are managing their best to help the deaf children. Case 11 A said;

Teachers have a good feeling about me. They sympathize that I do not participative like the other students. They try to understand my problem and attempt to communicate through writing. They see 
my exercise books with focus.

Besides, as good news teachers are ready to commit themselves in receiving sign language training. Case 7 enabled us to understand that;

Teachers have a good attitude about me. They often think how they will be able to communicate with me in the future. They are willing and interested to get training to develop sign language skills. They

\subsubsection{Interaction with peers} try to communicate in signing by the sign language training they received previously.

Respondents were asked, "How do you explain your interaction with your peers/classmates and how do you rate their attitude towards you?" The respondents provided mixed answers as their interaction was both favorable and unfavorable and the same thing is also true for the attitude part (the children rated the interaction and the attitude as good, to some extent good and not good).

Let us first see the positive experiences. Case 7 stated that;

The relationship of classmates with me is good. Often they tell me when there is class work and homework. During HPE class they are willing to play with me and we play together volley-ball. They have positive attitude towards me they allow me to participate in anything at any time.

The finding is consistent with other findings of the study in the country. For example, Abebe (2000) and Tadesse and Lynne (2015) indicated there is favorable interaction and attitude of peers towards deaf children. Whereas, Berhanie (2017) depicted there was less interaction of deaf children and peers had negative attitude towards deaf children.

Basically literatures state that, interaction is characterized by individuals providing and sharing ideas, cooperating with one another, challenging each other's conclusions, and reasoning in order to promote higher quality decisions (Mlay, 2010). However, in this study respondents revealed mixed reality.

When it comes to the negative experiences some respondents revealed their interaction with their peers as both good and bad. Meaning, some peers have positive attitude towards them and they are approachable and while others hold negative attitude and as a result they are unapproachable, engage in teasing and make fun of. Consequently, the deaf children prefer to alienate themselves and remain lonely. In this regard, case 5 stated that; My relationship with my classmates is somewhat good, because while some students have better attitude towards me and still some others tease and make fun of me. When I face this bad condition I become angry. I choose loneliness than contacting with students around.

Case 11A also shared similar experience. He said;

I have many classmate friends. Our relationship is only when we meet at school. They participate me in group and project works. Except few, majority have positive attitude. Few students laugh at me and they are not interested to play with me. However, generally speaking, I can say they have positive attitude.

The present study came up with consistent finding with studies such as Tadesse and Lynne (2015), Alasim (2018) and Mlay (2010) that revealed spoken language difficulties for deaf and hard of hearing students are the greatest barriers that limit the participation and interaction of the children with their peers. Regarding this reality, case 8 A stated;

I have no good relationship with my classmates. Usually, I establish relationship with deaf students and at break time I discuss with my ex-special unit teachers. I just simply mix myself in groups of students who sat for group discussion or class work, but I know I do not understand anything; that we cannot communicate with and understand each other.

Furthermore, case 9 reinforced what case 8A said. She underlined the urgency of sign language skills by all classmates/peers. She said;

....for the future to communicate well with my classmates, I will be very happy if sign language is widely accessible and signed.

Nevertheless, the study also indicated one finding that previous studies reviewed for this study never indicated. That is sign language skills that the deaf children acquired in special unit classes from grades 1 to 4 can be forgotten and hence it can pose a challenge in their interaction. Sending a message that continual updating in sign language through short term trainings should be arranged. Case 12 openly witnessed;

I am not that much good at sign language. Thus, I only have good communication with my parents at home through body language and writing. Though I have learnt sign language lessons when I was in grades 1 to 4, but I have difficulty remembering [signing] the language after 9 years. I am therefore, interested to improve the language in the future.

\subsubsection{Interaction with Teachers and School Communities}

The respondents were asked, "How do you rate your interaction with teachers and the school communities (for example, with guards)? Unlike the interaction of the deaf children with peers their interaction with teachers and school communities is positive and quite encouraging though there is communication barrier.

It can be said that the study came up with a finding which is consistent with findings of Asrat (2013) and 
Tadesse and Lynne (2015) that deaf children have a positive interaction with their teachers though they have communication barriers. Hence, it is possible to infer that the teachers' positive interaction with the respondents creates a positive emotional attachment on the side of deaf children that they are really cared as students by their teachers. That is what we see for example in case 6;

I have a good relationship with my teachers. We exchange greetings. They check my exercise books whether I have done or not homeworks and classworks. They allow me to seat in the front row when there is note writing. My teachers except that they have sign language barriers to support me, they have positive attitude.

The favorable interaction also goes beyond exchange of mere warmth, greetings and soft heart to day and night thinking of the teachers in what ways the deaf children can grow holistically. That is what we understand from case 7 . He said;

I think my relationship with my teachers is better because they engage me in different clubs and although what they teach me is not clear they always worry in what ways they could support me.

Case 8A further reinforced the reality from her observation how much the teachers are motivated to help out the deaf children though communication barrier is highly rampant. They use every means of the signing skills that they have received in short term trainings/briefings. She said;

My relationship with teachers is exchanging greetings through signing. Special unit teachers give short trainings every Friday when we line up for flag ceremony. Hence, my teachers try to communicate using that sign they got from the special unit teachers. This time I feel very happy. However, the teachers do not have sign language skills to give lessons in signs. Thus, in classworks and homeworks we [the deaf students] do not work as things are not clear for us.

The above finding, in relation to the impact of training on teachers' attempt of communication and awareness, is a consistent finding with Alasim (2018) who indicated, positive interaction can prevail if necessary awareness creation and equipment with relevant skills is made among teachers and school communities.

With regard to the interaction of the deaf children with the school communities such as principals and the guards of the schools, it was reported that there was also good interaction as has been so with teachers. The favorable interactions of the school communities with the deaf children that were expressed by deaf students have the following manifestations. School communities are willing to support the deaf children at any time, to minimize the communication barrier utilization there is use of body language, giving protection, giving priority and worry all the time for better academic performance of the deaf children. It was understood that all the mentioned manifestations were the result of awareness trainings especially the sign language displays on Fridays.

Let us see the manifestations case by case. The school communities are interactive and willing to support the deaf children making the school life very easy for the children. This we can understand from the response of case 7. He said;

I can use what I want in the shahi kibeb (lounge). I exchange greetings with the school principal and homeroom teachers. I have good relationship with the guards of the school. The guards have similar attitude for us as they have for other students of the school. They always try to support us. They have never done anything bad to harm us.

The support of the community is also accompanied with all the necessary protections. Case 8A narrated happily. She said;

We have good relationships with all the school communities. For example, guards try to communicate with us through body languages. When we are late they allow us to enter to the school.

They also protect us when other students show signs to bully us.

Not only protection, the school communities also worry about the academic performance of the deaf children. Case 11B depicted;

I have good relationship with all the school community, because I can get all the services available in school like the other students. They have positive attitude. They are always worrying that we do not communicate in sign language. When I have lower achievements they often regret and anxious how to communicate in the future. They do not stigmatize me.

Above all, the favorable interaction of the deaf children with the school community has opened the children for privileges to get the first priority. In relation to this, case 6 stated that;

I have good relationship with the school community. They try to communicate with me through body language. This time I feel very happy. Our interaction with the school community often occurs and it is good during break time and entering to the school and the class. When I want to drink water the guards give me the first chance.

\subsection{Physical Inclusion}

\subsubsection{Teaching and Learning Materials}

The deaf children were asked, "Do you feel you have all the necessary materials you need for your 
education?" Almost all the respondents replied that they are accessible with the necessary materials such as textbooks, exercise books and pens. Parents of the respondent children were capable enough to provide similar materials as reported by the respondents. For example, case 9 witnessed that;

The learning materials that I want are exercise book, text book, pen and other materials; my parents bought me exercise books, the school has also gave me 5 exercise books as a gift and I am also allowed to use other materials in the special unit resource center.

Another blessing in this year was that First Lady Zinash Tayachew of Ethiopia had made an offer of gifts for deaf children in Gondar City Administration as case 9 in the above also mentioned. Case 6 witnessed that;

In this year 2011 E.C [2019 G]), I have received learning material support by First Lady [Zinash Tayachew of Ethiopia]. In our school there is library and laboratory I can also use that except language barrier.

But, it does not mean that the children are accessible with all the materials what the literature recommends. For example Posi (2006) recommends, deaf children should be accessible to text and reference books, wall maps, charts and science kits. The crux of the matter is, respondents are totally happy in terms of the current access to the learning materials; considered as a great improvement which was not the case some three years ago. For example, Tadesse and Lynne (2015) in their study indicated, most (70\%) deaf children indicated there were insufficient learning materials. In fact, in all the respondents responded, "This year we do not have problems of materials."

Nevertheless, it does not mean, all the deaf children are accessible with all the needed materials. And again it does not mean all the materials contain all the supportive substances required. For example, case $8 \mathrm{~A}$ demanded sign language books to be placed in the library as a reference;

...it is better to put sign language book in the library to use it and improve my language. In our school there are no teachers who use sign language resulting in the declining of my singing ability.

Case 7 requested additional jumping ropes and balls;

.... To help us to be participative enough in sport activities, I recommend additional jumping ropes and balls should be purchased.

Case 11B asked the incorporation of more pictures in the existing text books;

...Sometimes, I try to understand lessons by looking at the pictures in the text books. So in the future I recommend more pictures to be incorporated in all subject textbooks.

In the response of the respondents they confirmed that they have the possibility to borrow books in the library and or resource centers; which can be also considered as a great change compared to lack of it evidenced in previous researches. For example, Deginesh (2016) in her review of related literature confirmed that there is absence of resources centers in almost all public schools were deaf children attend their education.

\subsubsection{School Building and Infrastructure}

The deaf children were asked, "Are the buildings of the school comfortable to you? Are the classrooms that you attend your lessons comfortable? All the respondents are happy with classrooms; they all responded their classrooms are comfortable and they do not have any problems. For example, case 6 is happy with her classrooms having wide room, open window and enough air. She said;

The classroom I learn in is good for me, no harm so far. The design of the class room is so wide and hence it is so comfortable for all students. Our classroom has window and thus we get enough fresh air.

Case 7 reinforced what case 6 in the above said, he is not even burdened by the seize of the classroom, 50 students in his class; that the rooms are wide, easy to move around and with day to day cleaning by the guards. He narrated;

The classroom I learn in is not challenging. Though we are 50 students in the class the fact that the room is so wide moving around for group work and anything else too we face no difficulty. Mostly the guards clean the room.

When it comes to the school building and infrastructure the children are very happy with all the things of the schools. They are happy with the buildings of the school, the toilets, sport fields and shai kibeb (lounges). For example, case 6 narrated;

The school does not have cemented buildings, but to get in and out to and from the school and play outside I face no difficulties so far. We have teachers' and student's toilets when I want I can use.

Case 8A added her happiness with classrooms, sport field, recreation centers and the lounge. She said;

We do not have problems of chair and table. I am happy that we have sport field, study places, recreation centers, and Shahi Kibeb.

\subsubsection{Seating Arrangement}

The deaf children were asked, "Do your teachers permit you to seat where you feel you are comfortable with?" All respondents replied that all their teachers do allow them to seat wherever they want. Above all, though teachers use to arrange the seat of students based on 1 to 5 group arrangement through competence based 
mechanisms, they allow the deaf children to join any group in the classroom whenever they want. Case 6 narrated this scenario in the following manner;

I seat in front seat, based on 1 to 5 seating arrangements. However, if I want to seat with other groups or want to talk with friends in the class, I will change my seat; teachers do not have any problems.

Case 8B be added how much the permission to different seats is accompanied with special treatments too. She disclosed;

Teachers allow me to sit in any row I want. In fact, I prefer to sit in front of the blackboard. Some teachers do punish if they get a student out of his/her seat of his/her 1 to 5 group arrangement. However, for me this punishment has never happened when I change my seat.

In a nut shell, it is possible to infer that the seating arrangement practice that teachers of the deaf children apply is in line with what the literature suggests. For example, Van Udens (1977) suggested that, the number of students must be smaller in the class, proposing that five partners in the class is the optimum number for effective conversation. Some students may require lip reading to reach a normal level of comprehension and these will need preferential seating arrangements (Chimedza and Peterson, 2003; as cited in Gudyanga et.al, 2014). An effective seating arrangement can enable students who are deaf and hard-of-hearing to see other students and the teacher easily, to participate in both individual work and group activities and to follow classroom discussions easily (Trussell, 2008).

\section{Conclusion, Suggestion and Implication}

\subsection{Conclusion}

The deaf children were found to be socially included though there is communication barrier. The interaction of the deaf children with their teachers was positive and encouraging. The teachers, though they have communication barrier, they were found to be with positive attitude, accepting, caring and empathetic. When it comes to the interaction of the deaf children with the school communities such as the principal and the guards, similar to teachers though they have communication barriers, the school communities were found to be interactive, willing to support, protective and giving priority for the deaf children.

The deaf children are physically included with some limitations. The children have accessibility to different teaching-learning materials such as exercise books, text books, pen and they can use books in the library and resource centers. However, the quality of text books that the children provided with are with limitations that the text books are not containing as much pictorial presentations as needed by the respondents. In addition to this, there is also lack of adequate balls and jumping ropes for sport activities. With regard to school building and infrastructure, it was found that there were wide classrooms with adequate space and fresh air; the children are also provided with comfortable toilets, sport fields and lounges. In relation to seating arrangement, it was found that respondents were permitted to sit anywhere in the classroom where they felt comfortable.

\subsection{Suggestion}

Gondar City administration educational office and the school principals need to work together to make teachers, students and significant school communities to be able to have sign language skills through short and long term trainings and if possible sign language interpreters need to be recruited. Schools should make ensure that they have all the necessary materials with adequate number along with adequate training of their teachers in using effective and varied methodologies for teaching deaf children. At national levels when text books are prepared designers need to consider students with disabilities, in our case deaf children that sufficient pictorial presentations need to be incorporated.

\subsection{Implication}

Deaf children will be successfully included socially and physically if the following conditions are met: text books with sufficient pictorial presentations, interpreters presence and involvement in the class of the deaf children, mastery of sign language skills of all the school communities and if special needs teachers are always on the side of the deaf children. The latter is quite essential idea to all concerned stakeholders on deaf education in the country and we have to think of in the future those teachers who taught the deaf children grades 1 to 4 should not leave the children alone to proceed grades 5 to 12; rather they should be continuing monitoring, guiding and teaching the children. And future researches need to focus on the impact of the preceding areas of implications on the full inclusion of the deaf children and adults.

\section{References}

Abebe, G. 2000. Attitude of teachers and students regarding the integration of hearing impaired students into regular classes. Masters Theses, Addis Ababa University, Addis Ababa, Ethiopia.

Alasim, K. 2018. Participation and Interaction of deaf and hard-of-hearing students in inclusion classroom. 
International Journal of Special Education, 33(2):493-506.

Alemayehu, T. 2000. Sign language: Basic concepts and its structure. Education Journal. 4 (10): $44-70$.

.2016. Quality of interpretation services and its implications in creating inclusive classrooms for deaf preparatory school students. Eastern Africa Social Science. Research Review, 32 (2):103-122.

Allen, K. 2013. A hermeneutic phenomenological study of the lived experiences of individuals in intercultural relationships. Masters Theses, University of Regina, Regina, Canada.

Anonymous. 2016. Inclusive education for students with visual, hearing and physical disabilities: barriers and experiences in Gondar, Northern Ethiopia. Masters Thesis, University of Sheffield, Sheffield, United Kingdom.

Asrat, D. 2013. Factors affecting the implementation of inclusive education in primary schools of Bahir Dar Town Administration. Education Research Journal, 3(3):59-67.

Aseery, F. 2016. Teachers' attitudes toward the inclusion of deaf and hard of hearing students in regular education classrooms in Saudi Arabia. Doctoral Dissertation, Ball State University, Indiana, United States of America.

Aynie, B. 2016. Practices of special needs education teachers in teaching sign language to deaf students the case of North Showa Zone of Amhara Region. Masters Thesis, Addis Ababa University, Addis Ababa, Ethiopia.

Belay, T. Fantahun, A. and Missaye, M. 2015. Education of children with special needs in Ethiopia: Analysis of the rhetoric of 'Education ForAll' and the reality on the ground. The Ethiopian Journal of Education, XXXV(I): 45-97.

Berhanie, A. 2017. Challenges and experiences on inclusive physical education: The case of Bahir Dar elementary schools. International Journal of Physical Education, Sports and Health,4(2):94-99.

Creswell, J.W. (2013). Qualitative Inquiry \& Research Design: Choosing among Five Approaches. Los Angeles, CA: Sage.

Deginesh, D. and Asrat, W. 2016. Review of challenges of hearing impaired students in integrated class in public schools in Ethiopia: A review article. Journal of Medicine, Phsiology and Biophysics, 1(22):74-78.

Eriks-Brophy, A., Durieux-Smith, A., Olds, J., Fitzpatrick, E., Duquette, C., \& Whittingham, J. 2012. Communication, academic, and social skills of young adults with hearing loss. Volta Review, 112(1): 5-35.

Gudyanga, E. Wadesango, N. Hove, E. and Gudyanag, A. 2014. Challenges faced by students with hearing impairment in Bulawayo urban regular schools. Mediterrranean Journal of Social Sciences, 5(9): 445-451.

Hung, H., \& Paul, P. (2006). Inclusion of students who are deaf or hard of hearing: Secondary school hearing students' perspectives. Deafness and Education International, 8 (2), 62-74.

Mapsea, A.J. (2006). Teachers'Views on Providing for Children with Special Needs in Inclusive Classrooms. University of Waikato, Waikato, Papua New Guinea.

Mapolisa, T. (2013). The impact of inclusion of children with hearing impairment into regular schools: A case study of Dakamela primary school in Zimbabwe. International Journal of Asian Social Science, 3(7):15001510 .

Maxwell, J. A. (2005). Qualitative research design: An interactive approach (2nd ed.). Thousand Oaks, CA: SAGE

Mekonnen, M. Elina, L. and Hannu, S. 2018. Academic achievement and self-concept of deaf and hard-ofhearing and hearing students transitioning from the first to second cycle of primary school in Ethiopia. International Journal of Inclusive Education, -(-):1-15.

Ministry of Education. 2012. Special needs/inclusive education strategy. Addis Ababa, Ethiopia. Available at www.moe.gov.et

Ministry of Labor and Social Affairs (2010). Baseline study on the status of persons with disabilities and the influence of the Africa decade pronouncement in Ethiopia. Policies and program implementation. Final Report. Commissioned by the Secretariat of the African Decade of Persons with Disabilities.

Mlay, J. 2010. Interaction between learners who are hard of hearing and their hearing peers in physical education lessons: A case study of learners who are hard of hearing in physical education, Tanzania. Masters Theses, University of Oslo, Oslo, Norway.

Mulat, M. Savolaine, H., Lehtomaki, E. and Kuorelahti, M. 2015. Socio-emotional problems experienced by deaf and hard-of-hearing students in Ethiopia. Deafness and Education International. 1 (17): 155-162.

Mulat, M. Savolaine, H., Lehtomaki, E. and Kuorelahti, M. 2016. The self-concept of deaf/hard-of-hearing and hearing students. Journal of Deaf Studies and Deaf Education, 21(4):345-351.

Musengi, M. and Chireshe, R. 2012. Inclusion of deaf students in mainstream rural primary schools in Zombabwe: Challenges and opportunities. Stud Tribes Tribals, 10(2):107-116.

Nitsuh, B. 2008. Social interaction and participation of hearing impaired students in the regular classroom setting: The case of four hearing impaired students in Amhara Regional State, Ethiopia. Masters Theses, University of Oslo, Oslo, Norway. 
Padilla-Díaz, M. 2015. Phenomenology in educational qualitative research: Philosophy as science or philosophical science? International Journal of Educational Excellence, 1(2): 101-110.

Posi, M. K. (2006). From special to inclusive education to children in special needs in Tanzania: old wine in new bottle? Journal of Issues and Papers in Education, 1(2): 47 -63.

Prakash, S. 2012. Inclusion of children with hearing impairment in schools: A survey on teachers' attitudes. dcidj, 23(3): 90-111.

Schuemann, K. 2014. A phenomenological study into how students experience and understand the university presidency. Doctoral Dissertation, Western Michigan University, Michigan, United States of America.

Sunayna , B., Jihan, S., \&Joane, S. (2013). Mainstreaming disability: Literature study on the laws and policies regarding the rights of persons with disabilities in Ethiopia, India and Kenya. Master's thesis,Vrije University Amsterdam. Dutch Coalition.

Tadesse, A., and Lynne S. (2015). An assessment of factors affecting the education/inclusion of deaf and hardof-hearing students in North and South Gondar Zone integrated primary school classes. Ethiopian Renaissance Journal of Social Sciences and the Humanities, 2 (2):37-53.

Tibebu B. (1995). Meanings attached to disability. Attitudes towards disabled people and attitudes towards integration. Doctoral Dissertation, University of Jyvaskyla.

Tilahun, A. (2009). The schooling situation for hearing-impaired pupils in four regular schools of Bahir Dar and Debretabor towns. Master's thesis, Addis Ababa University, Addis Ababa, Ethiopia.

Tirussew, T. ( 2005). Disability in Ethiopia; issues, insights and implications. Addis Ababa, Addis Ababa University Press.

Trussell, R. P. (2008). Classroom universals to prevent problem behaviors. Intervention in School and Clinic, 43, $179-185$.

Van Uden (1977). A world of language for Deaf children Part I: Basic Principles (3 ${ }^{\text {rd }}$ ed). Amsterdam \& Lisse: Swets \& zeillinger

First Author: Tadesse Abera ( $\mathrm{PhD}$ candidate) - Department of Special Needs and Inclusive EducationHaramaya University, Ethiopia. Tel.0251-913-24-54-68 E-mail:peace4ujesus@gmail.com. MA in Special Needs Education from Addis Ababa University, Ethiopia. Lecturer in University of Gondar, Ethiopia.

Second Author: Dawit Negassa (PhD)- Department of Special Needs and Inclusive Education- Haramaya University, Ethiopia. Tel. 0251-912-79-97-66 E-mail:dawitnegassa2002@gmail.com. PhD in Special needs education from Addis Ababa University, Ethiopia. Currently, working as a dean in College of Education and Behavioral Sciences, Haramaya University. 